\title{
XXXII ${ }^{\text {nd }}$ INTERNATIONAL ASTIN COLLOQUIUM
}

\author{
Washington, D.C., United States of America
}

The XXXII ${ }^{\text {nd }}$ ASTIN Colloquium was held at the JW Marriott Hotel in Washington, D.C. from July 8 to 11,2001 . The capital city of the United States stimulated attendees with its broad avenues, striking architecture, inspiring monuments, and splendid museums.

The Colloquium was attended by about 192 participants from 25 countries and 26 accompanying persons. A welcoming reception took place on Sunday, July 8 on a rooftop terrace of the JW Marriott Hotel that offered magnificent views and a sociable ambience.

Edward Levay, the chairman of ASTIN, presided over the opening ceremony on Monday, July 9. David Skurnick, chairperson of the organizing committee, and Gary S. Patrik, chairperson of the scientific committee each addressed the attendees. Robert Conger, president-elect of the Casualty Actuarial Society delivered a warm welcome to the attendees. He stressed the common goals of ASTIN and the CAS, noting how the research goals of both organizations are strengthened when researchers work with practitioners in search of answers to real problems. Bob commented on the increasing global interest of many organizations in response to the growing globalization of the world's economy. He noted how the international reach of ASTIN contributes to the global awareness of our profession.

Following the opening ceremony, ASTIN was privileged to have Dr. Samuel Broder as its invited lecturer. Dr. Broder is the Executive Vice President of Celera Genomics, well known as the company to sequence the human genome. $\mathrm{He}$ is the former director of the National Cancer Institute at the National Institute for Health. His laboratory was instrumental in developing several of the drugs now widely used in the therapy of AIDS and its related disorders. Dr. Broder obtained his undergraduate and medical degrees from the University of Michigan. His internship and residency were at Stanford University.

Dr. Broder spoke to an attentive crowd about the challenges of sequencing the genome of the human species, as well as other species. He discussed the implications of this groundbreaking research on society in general, as well as on the insurance industry in particular. The remainder of the first morning was spent in four concurrent sessions during which a total of 10 papers were presented.

During the Monday afternoon sessions, attendees again had their choice of four concurrent sessions in which 10 additional papers were presented. In the late afternoon, proceedings continued with another four parallel sessions during which 11 papers were presented. The audiences then gathered together for the ASTIN General Assembly, and a reception and dinner.

On Tuesday morning, July 10, attendees were treated to their choice of four concurrent sessions, where 11 papers were presented. The second morning session on Tuesday offered attendees their choice between two sessions with 
three papers presented in each, or two different Speaker's Corner sessions. In total, 30 different papers were presented during the Colloquium.

The papers covered a broad array of topics. Several papers examined aspects of reserving, and a number explored financial modeling. The largest single category of papers examined a number of reinsurance topics, not surprising in view of the collaboration with the CAS Seminar on Reinsurance. Papers also dealt with aspects of globalization, and several papers addressed health and life topics.

Attendees enjoyed one of two half-day excursions on Tuesday afternoon. "The Splendor of Capitol Hill" tour found delegates visiting the U.S. Capitol Building, with its awe-inspiring 168 -foot dome rotunda, as well as the Supreme Court Building and the Library of Congress. The "Welcome to Washington" tour led delegates along the tree-lined Mall and past such striking landmarks as the White House, Washington Monument, Lincoln Memorial, Vietnam Veterans Memorial, Korean Veterans Memorial, Jefferson Memorial, FDR Memorial, and John F. Kennedy Center for the Performing Arts.

The ASTIN Colloquium was planned as a back-to-back event with the Casualty Actuarial Society's Seminar on Reinsurance, with Wednesday, July 11 featuring sessions jointly offered by the two programs. The morning began with the "Opening of Joint Seminar Day", followed by a General Session titled "A View from the Top: CEO's Discuss Where Actuarial Analysis Does and Does Not Provide Value to their Enterprise". The session was moderated by James Stanard and included Brian Duperreault and Mary Hennessy as panelists. The panelists discussed what types of actuarial analysis have helped achieve profitability and better manage their business, as well as what types of analysis have not worked well. At the end of this session a closing ceremony took place and the ASTIN flag was passed to Mexican delegates who will organize the XXXIII ${ }^{\text {rd }}$ Colloquium (Cancun, Mexico - March 17-19, 2002).

The Organizing Committee of the XXXII ${ }^{\text {nd }}$ ASTIN Colloquium wishes to thank all the participants who made the meeting so successful. Particularly, we would like to express our appreciation to all of the speakers, panelists and moderators for their contributions in presenting a quality program.

The Organizing Committee of the XXXII ${ }^{\text {nd }}$ ASTIN Colloquium 